\title{
Fuzzy BWANP multi-criteria decision-making method
}

\author{
Moslem Alimohammadlou ${ }^{\mathrm{a}^{*}}$ and Abbas Bonyani ${ }^{\mathrm{b}}$
}

\begin{abstract}
${ }^{a}$ Department of Industrial Management, Faculty of Economic, Management and Social Science, Shiraz University, Shiraz, Iran ${ }^{b}$ Department of Industrial Management, Faculty of Management and Accounting, Allameh Tabataba'i University, Tehran, Iran

C H R O N I C L E

Article history:

Received November 18, 2017

Received in revised format:

January 8, 2018

Accepted April 23, 2018

Available online

April 23, 2018

Keywords:

Decision-Making

Fuzzy Analytic Network Process

Fuzzy Best-Worst Method

A B S T R A C T

Fuzzy Analytical Network Process (F-ANP) method is able to consider the complex relationships among different levels of decisions, transactions, and feedbacks of criteria and alternatives to calculate the weights of the elements. The large number of pair-wise comparisons in F-ANP and also difficulties in understanding the way of comparisons for the expert, have reduced the efficiency and practicality of this method. In this paper, in order to eliminate the above-mentioned problems, it has been tried to provide an approach using the Fuzzy Best-Worst method, called F-BWANP. The proposed method, requires less comparison data and leads to more consistent comparisons, which means that more reliable results can be obtained, while making it much easier for responding by experts. Finally, in order to describe the proposed method and evaluate its capability, a numerical example is provided.
\end{abstract}

C) 2019 by the authors; licensee Growing Science, Canada.

\section{Introduction}

Saaty (1996), when seeking a solution for limitations of Analytic Hierarchy Process (AHP) and its inability in applying dependencies between criteria and factors, developed another approach, which was known as Analytic Network Process (ANP). Analytic Network Process approach is an extension of AHP or in other words, its general form. AHP models the decision structure through indirect hierarchical relationships among the criteria; but, ANP provides the possibility to evaluate more complex internal relationships among the criteria. The development of this process was aimed at providing more realistic conditions for decision-making, without considering the assumptions about one-way hierarchical relationship among decision levels (Sipahi \& Timor, 2010). In the other words, AHP considers the one-way relationships among decision levels, while ANP, considers the mutual relationships among decision levels and features in a more general situation (Agarwal et al., 2006). Therefore, ANP can be applied as an effective tool in situations, in which the transactions among elements of a system form a network (Saaty, 2001). ANP uses the relative scales based on pair-wise comparisons. However, it does not apply the limited hierarchical structure similar to the AHP, and models the decision-making problem using the systematic approach with feedback. Although the Fuzzy ANP was also introduced as a more accurate method for modeling the complicated decision environments, the following problems can be seen in it (Yu \& Tzeng, 2006):

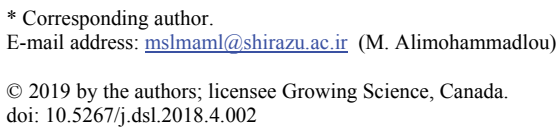


- It is difficult to provide a correct network structure even for experts, and different structures lead to different results.

- To form a super-matrix all criteria, have to be pair-wise compared with regard to all other criteria, which is also difficult and somewhat unnatural, as we ask themselves questions of the type: "How much is a criterion A more important than a criterion B with regard to a criterion C?"

- Large number of pair-wise comparisons: to calculate eigenvectors, pair-wise comparisons are required, resulting in a significant increase in pair-wise comparisons.

In this paper, the F-BWANP method is presented as the alternative of F-ANP that while having a rational procedure, can possible cover the problems of above-mentioned method.

\section{Literature review}

Analytic Network Process can be applied in many areas (Saaty, 2005; Vargas, 2006; Saaty \& Brandy, 2009). ANP is further used in areas including, Decision making, Evaluation, selection QFD, Planning and Development, Priority and Ranking, and Forecasting. There are many research works in this area and we address some of them (Hülle et al., 2013). In their work, Chen et al. (2006) used ANP method for generating a location selection model to determine the best location out of a choice of three alternatives for a biotech park in Taiwan. They suggested two ANP models that consider the environmental issues, and then, the two method were combined to select the best plan out of the three ones. Cheng et al. (2005) used the ANP and AHP to select the best shopping mall location.

Chen and Chen (2009) examined the critical factors, affecting the quality improvement in the Taiwanese banking industry. Aznar et al. (2010) applied ANP to evaluate the urban properties. Chen et al. (2008) proposed a method in which the ANP can be used in form of a knowledge-framed analytic network process (KANP) to evaluate contractor candidates in an open competition to procure a construction project. ANP has also been used in the area of planning and development. In their work, Lee et al. (2008) and Chen et al (2008) used ANP for product development. ANP has also been used for energy policy planning by Hämäläinen and Seppäläinen (1986).

ANP was used by Cheng and Li (2005) for prioritizing a set of projects. Suitable enterprise architecture was presented by Wadhwa et al. (2009) for virtual enterprises and virtual manufacturing focused on agility. In order to model the mutual relationship between different decision areas for prioritizing the enterprise-wide flexibility dimensions, ANP was used. Lee et al. (2008) tried to improve the technology foresight by using ANP. Crowe and Lucas-Vergona (2007) investigated the problem of excessive illegal immigration. They used ANP in order to create a decision model based on economic, social, political and environmental factors to make decision among six alternatives. Zoffer et al. (2008) studied an issues related to the conflict in Middle East and a possible road-map to the Middle East peace process. ANP was used by the authors in order to evaluate the conflict around the world and to synthesize judgement for finding an optimal conflict solution. Wu et al. (2009) used ANP for its ability to integrate the relationships among decision levels. Blair et al. (2002) analyzed expert judgement regarding prediction of the resumption of the American Economic development's growth, using the ANP. Chang et al. (2009a) investigated a manufacturing model for predicting the presence of a silicon wafer using an ANP framework. In order to improve clients' satisfaction, Buyukozkan et al. (2004) applied QFD for translating their needs into technical design requirements. In order to prioritize the design requirements as a part of the house of quality ANP approach was used. Pal et al. (2007) proposed an integrated method using ANP and QFD. This approach was used to determined and prioritize the engineering needs about a cast part to select a suitable, rapid prototype-based route to tool manufacturing. As it was seen, ANP was considered by many researchers and has been used in various fields. Some researchers have sought to combine this method with other methods for better use of ANP, resulting in ISM-ANP and D-ANP methods that tries to improve the relations matrix in ANP (Chang et al., 2013), or GP-ANP that attempts to obtain better results from ANP (Chang et al., 2009b). But, the issue which is challenging in all the mentioned methods is the large number of comparisons and 
calculations and the difficulty of responding by the experts. In this paper, the F-BWANP method is provided, through which, while achieving more relatable results, the pair-wise comparisons would be facilitated and reduced.

\section{The proposed F-BWANP method}

Like the F-ANP, F-BWANP first calculates Eigenvectors and then, a super-matrix is formed, but, the difference between the two methods is how to calculate eigenvectors. F-ANP uses the pair-wise comparisons of F-AHP to calculate eigenvectors, resulting in significant increase in pair-wise comparisons. F-BWANP has eliminated the problem and uses the F-BWM comparisons in order to calculate eigenvectors (Guo \& Zhao, 2017) that needs less comparison data, while leading to a more reliable comparison, and it means that F-BWANP gives more reliable answers. Therefore, to calculate the eigenvector, first, the best (most important) and worst (least important) criterion should be determined and then, the preference of the best criterion over all the other criteria $\left(\tilde{a}_{B j}\right)$ and also the preference of all the other criteria over the worst criterion $\left(\tilde{a}_{j W}\right)$ are determined and the criteria's weight is calculated according to the F-BWM method. In the other words, all elements of F-AHP pair-wise comparisons matrix are not needed to calculate the eigenvector, and only one row and one column of it are needed, namely the row and column representing $\tilde{a}_{B j}$ and $\tilde{a}_{j W}$. In F-BWANP, only this row and column is calculated. After determining $\tilde{a}_{B j}$ and $\tilde{a}_{j W}$, the model is formulated in form of a linear programming problem and solved. In this approach, the comparisons are considerably reduced.

\section{Steps of F-BWANP method}

1. The decision problem is decomposed into its decision elements and structured into a hierarchy that includes an overall goal, criteria, sub criteria, and alternatives, with the number of levels varying depending on the complexity of the problem and the number of factors to be considered.

2. Using pair-wise comparisons:

Table 1

Transformation rules of linguistic variables ofdecision-makers

\begin{tabular}{cc}
\hline Linguistic terms & Membership function \\
\hline Equally importance & $\left(\begin{array}{lll}1 & 1 & 1\end{array}\right)$ \\
Weakly important & $\left(\begin{array}{lll}2 / 3 & 1 & 3 / 2\end{array}\right)$ \\
Fairly important & $\left(\begin{array}{lll}3 & 2 & 5 / 2\end{array}\right)$ \\
Very important & $\left(\begin{array}{lll}5 / 2 & 3 & 7 / 2\end{array}\right)$ \\
Absolutely important & $(7 / 2 \quad 4 \quad 9 / 2)$ \\
\hline
\end{tabular}

2.a. Determine the best (most important) criterion and Execute the fuzzy reference comparisons for the best criterion. By using the linguistic terms of decision-makers listed in Table 1, the fuzzy preferences of the best criterion over all the criteria can be determined. Then, the obtained fuzzy preferences are transformed to TFNs according to the transformation rules shown in Table 1. The obtained fuzzy Bestto-Others vector is (Sadjadi \& Karimi, 2018):

$$
\tilde{A}_{B}=\left(\tilde{a}_{B 1} \cdot \tilde{a}_{B 2} \cdot \ldots . \tilde{a}_{B n}\right) \quad \text { where } \tilde{a}_{B j}=\left(l_{B j} \cdot m_{B j} \cdot u_{B j}\right)
$$

2.b. Determine the worst (least important) criterion and Execute the fuzzy reference comparisons for the worst criterion. By using the linguistic evaluations of decision-makers listed in Table 1, the fuzzy preferences of all the criteria over the worst criterion can be determined, and then they are transformed to TFNs according to the transformation rules listed in Table 1. The fuzzy Others-to-Worst vector can be obtained as:

$$
\tilde{A}_{W}=\left(\tilde{a}_{1 W} \cdot \tilde{a}_{2 W} \cdot \ldots . \tilde{a}_{n W}\right) \quad \text { where } \quad \tilde{a}_{j W}=\left(l_{j W} \cdot m_{j W} \cdot u_{j W}\right)
$$

3. Determine the optimal fuzzy weights. The optimal fuzzy weight for each criterion is the one where, for each fuzzy pair $\widetilde{w}_{B} / \widetilde{w}_{j}$ and $\widetilde{w}_{j} / \widetilde{w}_{W}$, it should have $\widetilde{w}_{B} / \widetilde{w}_{j}=\widetilde{a}_{B j}$ and $\widetilde{w}_{j} / \widetilde{w}_{W}=\tilde{a}_{j W}$. To satisfy these conditions for all $\mathrm{j}$, it should determine a solution where the maximum absolute gaps $\mid \frac{\widetilde{W}_{B}}{\widetilde{W}_{j}}-$ 
$\tilde{a}_{B j} \mid$ and $\left|\frac{\widetilde{W}_{j}}{\widetilde{W}_{W}}-\tilde{a}_{j W}\right|$ for all $j$ are minimized. Therefore, we can obtain the constrained optimization problem for determining the optimal fuzzy weights $\left(\widetilde{w}_{1}^{*} \cdot \widetilde{w}_{2}^{*} \ldots . \widetilde{w}_{n}^{*}\right)$ as follows:

$$
\begin{aligned}
& \min \max _{j}\left\{\left|\frac{\widetilde{W}_{B}}{\widetilde{W}_{j}}-\tilde{a}_{B j}\right| \cdot\left|\frac{\widetilde{W}_{j}}{\widetilde{W}_{W}}-\tilde{a}_{j W}\right|\right\} \\
& \left\{\begin{array}{l}
\sum_{j=1}^{n} R\left(\widetilde{w}_{j}\right)=1 \\
l_{j}^{w} \leq m_{j}^{w} \leq u_{j}^{w} \\
l_{j}^{w} \geq 0 . j=1.2 \ldots . n
\end{array}\right.
\end{aligned}
$$

where

$$
\begin{aligned}
& \widetilde{W}_{B}=\left(l_{B}^{w} \cdot m_{B}^{w} \cdot u_{B}^{w}\right) \cdot \widetilde{W}_{j}=\left(l_{j}^{w} \cdot m_{j}^{w} \cdot u_{j}^{w}\right) \cdot \widetilde{W}_{W}=\left(l_{W}^{w} \cdot m_{W}^{w} \cdot u_{W}^{w}\right) \\
& \tilde{a}_{B j}=\left(l_{B j} \cdot m_{B j} \cdot u_{B j}\right) \cdot \tilde{a}_{j W}=\left(l_{j W} \cdot m_{j W} \cdot u_{j W}\right)
\end{aligned}
$$

Eq. (3) can be transferred to the following nonlinearly constrained optimization problem:

$$
\begin{aligned}
& \min \tilde{\xi} \\
& \left\{\begin{array}{l}
\left|\frac{\widetilde{W}_{B}}{\widetilde{W}_{j}}-\tilde{a}_{B j}\right| \leq \tilde{\xi} \\
\left|\frac{\widetilde{W}_{j}}{\widetilde{W}_{W}}-\tilde{a}_{j W}\right| \leq \tilde{\xi} \\
\sum_{j=1}^{n} R\left(\widetilde{w}_{j}\right)=1 \\
l_{j}^{w} \leq m_{j}^{w} \leq u_{j}^{w} \\
l_{j}^{w} \geq 0 . j=1.2 \ldots . . n
\end{array}\right.
\end{aligned}
$$

where $\tilde{\xi}=\left(l^{\xi} \cdot m^{\xi} \cdot u^{\xi}\right)$

\begin{tabular}{|c|c|c|c|c|c|}
\hline Linguistic terms & Equally importance & Weakly important & Fairly important & Very important & Absolutely important \\
\hline$\widetilde{a}_{B W}$ & $\left(\begin{array}{lll}1 & 1 & 1\end{array}\right)$ & $\left(\begin{array}{lll}2 / 3 & 1 & 3 / 2\end{array}\right)$ & $\left(\begin{array}{lll}3 / 2 & 2 & 5 / 2\end{array}\right)$ & $\left(\begin{array}{lll}5 / 2 & 3 & 7 / 2\end{array}\right)$ & $(7 / 249 / 2)$ \\
\hline CI & 3 & 3.8 & 5.29 & 6.69 & 8.04 \\
\hline
\end{tabular}

Considering $l^{\xi} \leq m^{\xi} \leq u^{\xi}$, we suppose $\tilde{\xi}^{*}=\left(k^{*} \cdot k^{*} \cdot k^{*}\right) \cdot k^{*} \leq l^{\xi}$, then Eq. (4) can be transferred as:

$$
\begin{aligned}
& \min \tilde{\xi}^{*} \\
& \left\{\begin{array}{l}
\left|\frac{\left(l_{B}^{w} \cdot m_{B}^{w} \cdot u_{B}^{w}\right)}{\left(l_{j}^{w} \cdot m_{j}^{w} \cdot u_{j}^{w}\right)}-\left(l_{B j} \cdot m_{B j} \cdot u_{B j}\right)\right| \leq\left(k^{*} \cdot k^{*} \cdot k^{*}\right) \\
\left|\frac{\left(l_{j}^{w} \cdot m_{j}^{w} \cdot u_{j}^{w}\right)}{\left(l_{W}^{w} \cdot m_{W}^{w} \cdot u_{W}^{w}\right)}-\left(l_{j w} \cdot m_{j W} \cdot u_{j W}\right)\right| \leq\left(k^{*} \cdot k^{*} \cdot k^{*}\right) \\
\sum_{j=1}^{n} R\left(\widetilde{w}_{j}\right)=1 \\
l_{j}^{w} \leq m_{j}^{w} \leq u_{j}^{w} \\
l_{j}^{w} \geq 0 \cdot j=1.2 \ldots . n
\end{array}\right.
\end{aligned}
$$

\section{Table 2}

Consistency index (CI) 
The obtained consistency index (CI) with regards to different linguistic terms of decision-makers for fuzzy BWM are listed in Table 2 . We then calculate the consistency ratio, using $\tilde{\boldsymbol{\xi}}^{*}$ and the corresponding consistency index, as follows:

$$
C R=\frac{\tilde{\xi}^{*}}{C I}
$$

4. form the super-matrix. The general form of the super-matrix can be described as follows:

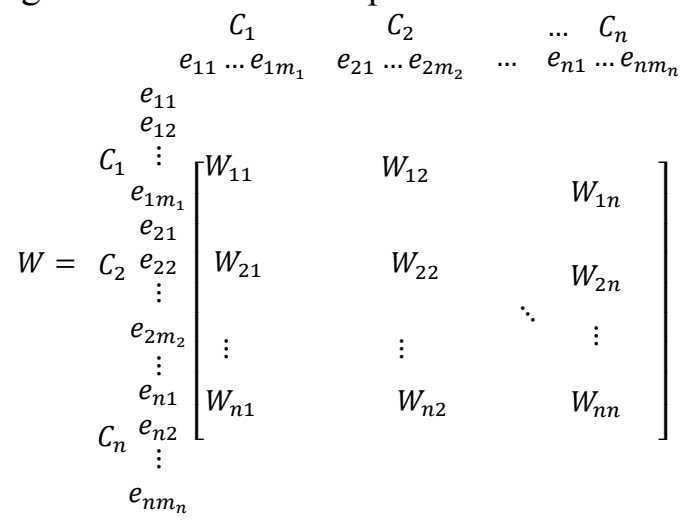

where $C_{m}$ denotes the $m$ th cluster, $e_{m n}$ denotes the $n$th element in the $m$ th cluster, and $W_{i j}$ is the principal eigenvector of the influence of the elements compared in the $j$ th cluster to the $i$ th cluster. In addition, if the $j$ th cluster has no influence on the $i$ th cluster, then $W_{i j}=0$. After forming the super-matrix, the weighted super-matrix is derived by transforming all column sums to unity exactly. Next, we raise the weighted super-matrix to limiting powers such as Eq. (7) to get the global priority vectors or so-called weights:

$\lim _{k \rightarrow \infty} W_{w}^{k}$

In addition, if the super-matrix has the effect of cyclicity, the limiting super-matrix is not the only one. There are two or more limiting supermatrices in this situation and the Cesaro sum would be calculated to get the priority. The Cesaro sum is formulated as:

$$
\lim _{k \rightarrow \infty}\left(\frac{1}{N}\right) \sum_{r=1}^{N} W_{r}^{k}
$$

to calculate the average effect of the limiting super-matrix (i.e., the average priority weights) where $W_{r}$ denotes the $r$ th limiting super-matrix. Otherwise, the super-matrix would be raised to large powers to get the priority weights (Saaty, 1996).

\section{Case study}

In order to evaluate the capabilities of the proposed method, a case study is provided. To this end, the performance of companies in the area of product development is evaluated (in USA 2017). Criteria and decision-making alternatives are as follows:

\section{Table 3}

The criteria and companies

\begin{tabular}{lc}
\hline & Company \\
\hline A1 & TechAhead \\
\hline A2 & Parangat Technologies \\
A3 & OpenXcell \\
A4 & LeewayHertz \\
\hline
\end{tabular}

\begin{tabular}{cc}
\hline Criteria & \\
\hline $\mathrm{C} 1$ & Financial factors \\
$\mathrm{C} 2$ & Behavioral-cultural factors \\
$\mathrm{C} 3$ & Environmental factors \\
$\mathrm{C} 4$ & Organizational factors \\
$\mathrm{C} 5$ & Management factors \\
$\mathrm{C} 6$ & Risk factors \\
\hline
\end{tabular}


In the following, calculations of F-BWANP approach are provided. Before implementing the method, the relation matrix of criteria is extracted using the ISM method, which is described as follows (see Table 4). The matrix represents the internal dependencies of criteria to calculate W22.

Table 4

Final reachability matrix

\begin{tabular}{lcccccc}
\hline & $C 1$ & $C 2$ & $C 3$ & $C 4$ & $C 5$ & $C 6$ \\
\hline$C 1$ & 1 & 0 & 0 & $1^{*}$ & $1^{*}$ & $1^{*}$ \\
$C 2$ & 1 & 1 & 0 & $1^{*}$ & $1^{*}$ & $1^{*}$ \\
$C 3$ & 1 & 1 & 1 & $1^{*}$ & 1 & $1^{*}$ \\
$C 4$ & $1^{*}$ & 0 & 0 & 1 & $1^{*}$ & $1^{*}$ \\
$C 5$ & $1^{*}$ & 0 & 0 & $1^{*}$ & 1 & $1^{*}$ \\
$C 6$ & 0 & 0 & 0 & 0 & 0 & 1 \\
\hline
\end{tabular}

\section{Calculation of matrix W21:}

The matrix W21 is the eigenvector, representing the importance of criteria with regard to the goal. According to the experts, the most important criterion is C8 and the least important criterion is C11 that their comparison with other criteria is provided in Table 5. The calculations related to determining the Weights of matrix W21 are provided in Table 7.

Table 5

Pair-wise comparisons of criteria with the best and the worst criterion

\begin{tabular}{|c|c|c|c|c|c|}
\hline & $\mathrm{C} 1$ & $\mathrm{C} 3$ & $\mathrm{C} 4$ & $\mathrm{C} 5$ & C6 \\
\hline BEST: C2 & $\left(\begin{array}{lll}5 / 2 & 3 & 7 / 2\end{array}\right)$ & $\left(\begin{array}{lll}5 / 2 & 3 & 7 / 2\end{array}\right)$ & $\left(\begin{array}{lll}3 / 2 & 2 & 5 / 2\end{array}\right)$ & $\left(\begin{array}{lll}2 / 3 & 1 & 3 / 2\end{array}\right)$ & $(7 / 2 \quad 4 \quad 9 / 2)$ \\
\hline & $\mathrm{C} 1$ & $\mathrm{C} 3$ & $\mathrm{C} 4$ & $\mathrm{C} 5$ & \\
\hline WORST: C6 & $\left(\begin{array}{lll}2 / 3 & 1 & 3 / 2\end{array}\right)$ & $\left(\begin{array}{lll}2 / 3 & 1 & 3 / 2\end{array}\right)$ & $\left(\begin{array}{lll}3 / 2 & 2 & 5 / 2\end{array}\right)$ & $\left(\begin{array}{lll}5 / 2 & 3 & 7 / 2\end{array}\right)$ & \\
\hline
\end{tabular}

Table 6

Modeling and solving the model

\begin{tabular}{|c|c|c|c|}
\hline $\min \mathrm{k}$ & & $k$ & 0.296548 \\
\hline & $\left|l_{l-} 0.67^{*} u_{6}\right| \leq k^{*} u_{6}$ & $l_{1}$ & 0.08567 \\
\hline 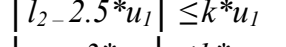 & $\left|m_{1-} 1^{*} m_{6}\right| \leq k^{*} m_{6}$ & $m_{1}$ & $\begin{array}{l}0.099898 \\
0101532\end{array}$ \\
\hline$\left|m_{2-} 3 * m_{1}\right| \leq k^{*} m_{1}$ & $\left|u_{1-} 1.5 * l_{6}\right| \leq k * l_{6}$ & $\begin{array}{l}u_{1} \\
l_{2}\end{array}$ & $\begin{array}{l}0.101532 \\
0.283938\end{array}$ \\
\hline$\left|u_{2-} 3.5 * l_{l}\right| \leq k * l_{1}$ & $\left|l_{3-} 0.67^{*} u_{6}\right| \leq k^{*} u_{6}$ & $m_{2}$ & 0.324368 \\
\hline$\left|l_{2-} 2.5^{*} u_{3}\right| \leq k^{*} u_{3}$ & $\left|m_{3-} l^{*} m_{6}\right| \leq k^{*} m_{6}$ & $u_{2}$ & 0.32525 \\
\hline$\left|m_{2-} 3^{*} m_{3}\right| \leq k * m_{3}$ & $\left|u_{3-} 1.5 * l_{6}\right| \leq k * l_{6}$ & $l_{3}$ & $\begin{array}{c}0.08567 \\
0.098396\end{array}$ \\
\hline$\left|u_{2}-3.5 * l_{3}\right| \leq k * l_{3}$ & $\left|l_{4-} 1.5 * u_{6}\right| \leq k^{*} u_{6}$ & $\begin{array}{l}m_{3} \\
u_{3}\end{array}$ & 0.098350 \\
\hline$\left|l_{2-1} 1.5^{*} u_{4}\right| \leq k^{*} u_{4}$ & $\left|m_{4-} 2^{*} m_{6}\right| \leq k^{*} m_{6}$ & $l_{4}$ & 0.1475 \\
\hline$\left|m_{2-} 2^{*} m_{4}\right| \leq k^{*} m$ & $\left|u_{4-} 2.5 * l_{6}\right| \leq k * l_{6}$ & $\begin{array}{l}m_{4} \\
u_{4}\end{array}$ & $\begin{array}{c}0.1475 \\
0.170496\end{array}$ \\
\hline$\left|u_{2}-2.3 \tau_{4}\right| \leq k^{*} u_{4}$ & $\left|l_{5-} 2.5 * u_{6}\right| \leq k^{*} u_{6}$ & $l_{5}$ & 0.247766 \\
\hline$\left|l_{2-} 0.67^{*} u_{5}\right| \leq k^{*} u_{5}$ & $\left|m_{5-} 3^{*} m_{6}\right| \leq k^{*} m_{6}$ & $m_{5}$ & 0.250179 \\
\hline \begin{tabular}{|l}
$\left|m_{2-} l^{*} m_{5}\right| \leq k^{*} m_{5}$ \\
$u_{2-}-1.5 * l_{5} \mid \leq k * l_{5}$
\end{tabular} & $\left|u_{5-} 3.5 * l_{6}\right| \leq k * l_{6}$ & $\begin{array}{l}u_{5} \\
l_{6}\end{array}$ & $\begin{array}{l}0.293765 \\
0.077377\end{array}$ \\
\hline 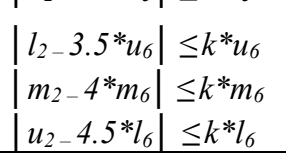 & $\begin{array}{l}1 / 6 * l_{1}+4 / 6 * m_{1}+1 / 6 * u_{1}+\ldots=1 \\
l_{1} \leq m_{1} \leq u_{1}, \ldots, l_{6} \leq m_{6} \leq u_{6} \\
l_{1}>0, \ldots, l_{6}>0\end{array}$ & $\begin{array}{l}m_{6} \\
u_{6}\end{array}$ & $\begin{array}{l}0.077377 \\
0.088635\end{array}$ \\
\hline
\end{tabular}


Table 7

Deffuzified weights

\begin{tabular}{lcc}
\hline$C R$ & 0.036884 & for all experts \\
\hline$W_{C 1}$ & 0.097799 & 0.105799 \\
$W_{C 2}$ & 0.317777 & 0.287777 \\
$W_{C 3}$ & 0.096798 & 0.103798 \\
$W_{C 4}$ & 0.151333 & 0.160333 \\
$W_{C 5}$ & 0.257041 & 0.261041 \\
$W_{C 6}$ & 0.079253 & 0.081253 \\
\hline
\end{tabular}

\section{Calculation of matrix W22}

This matrix compares the criteria based on each criterion. In this step, in order to determine the internal dependency of criteria, ISM method is used. Calculations related to the criteria's weights are based on C1 shown in Table 8 and Table 9. The operation is also performed for the other criteria, and its final result can be seen in Table 11 .

\section{Table 8}

Pair-wise comparisons of criteria with the best and the worst criteria based on $\mathrm{C} 1$

\begin{tabular}{|c|c|c|c|c|}
\hline & $\mathrm{C} 3$ & C4 & C5 & C6 \\
\hline BEST: C2 & $\left(\begin{array}{lll}3 / 2 & 2 & 5 / 2\end{array}\right)$ & $\left(\begin{array}{lll}2 / 3 & 1 & 3 / 2\end{array}\right)$ & $\left(\begin{array}{lll}1 & 1 & 1\end{array}\right)$ & $(5 / 2337 / 2)$ \\
\hline
\end{tabular}

\begin{tabular}{|c|c|c|c|}
\hline & $\mathrm{C} 3$ & C4 & C5 \\
\hline WORST: C6 & $\left(\begin{array}{lll}1 & 1 & 1\end{array}\right)$ & $(2 / 3 \quad 1 \quad 3 / 2)$ & $(3 / 225 / 2)$ \\
\hline
\end{tabular}

\section{Table 9}

Modeling and solving the model-Eigenvector based on $\mathrm{C} 1$

\begin{tabular}{|c|c|c|c|}
\hline Min $\mathrm{k}$ & & $k$ & 0.5615528 \\
\hline$\left|l_{2-} 1.5^{*} u_{3}\right| \leq k^{*} u_{3}$ & $\left|l_{3-} l^{*} u_{6}\right| \leq k^{*} u_{6}$ & $l_{2}$ & 0.284965 \\
\hline$\left|m_{2-} 2 * m_{3}\right| \leq k^{*} m_{3}$ & $\left|m_{3-}{ }^{*} m_{6}\right| \leq k^{*} m_{6}$ & $m_{2}$ & 0.284965 \\
\hline$\left|u_{2}-2.5 * l_{3}\right| \leq k * l_{3}$ & $\left|u_{3-} 1 * l_{6}\right| \leq k * l_{6}$ & $u_{2}$ & 0.3433966 \\
\hline$\left|l_{2-} 0.67 * u_{4}\right| \leq k * u_{4}$ & $l_{4-} 0.67 * u_{6} \mid \leq k^{*} u_{6}$ & $l_{3}$ & 0.1606736 \\
\hline$\left|m_{2-} 1 * m_{4}\right| \leq k * m$ & $m_{4-} l * m_{6} \mid \leq k^{*} m_{6}$ & $m_{3}$ & 0.1606736 \\
\hline$u_{2-} 1.5 * l_{4} \mid \leq k * l_{4}$ & $u_{4-} 1.5 * l_{6} \mid \leq k * l_{6}$ & $u_{3}$ & 0.1606736 \\
\hline$\left|l_{2-} l^{*} u_{5}\right| \leq k^{*} u_{5}$ & $l_{5-} 1.5 * u_{6} \mid \leq k * u_{6}$ & $l_{4}$ & 0.172637 \\
\hline$\left|m_{2-} *^{*} m_{5}\right|<k * m_{5}$ & $\begin{array}{l}l_{5-1.5} u_{6} \leq k^{*} u_{6} \\
m_{5} 2 * m_{6} \mid<k * m_{6}\end{array}$ & $m_{4}$ & 0.1824882 \\
\hline$\left|m_{2}-1 m_{5}\right| \leq k-m_{5}$ & $m_{5-2} m_{6} \mid=k \cdot m_{6}$ & $u_{4}$ & 0.2353592 \\
\hline 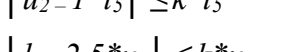 & $u_{5}-2 . J \cdot l_{6} \mid=k \cdot l_{6}$ & $l_{5}$ & 0.2333901 \\
\hline$\left|l_{2-} 2.5^{*} u_{6}\right| \leq k^{*} u_{6}$ & $1 / 6 * l_{2}+4 / 6 * m_{2}+1 / 6 * u_{2}+\ldots=1$ & $m_{5}$ & 0.2333901 \\
\hline$\left|m_{2-} 3 * m_{6}\right| \leq k * m_{6}$ & $l_{2} \leq m_{2} \leq u_{2}, \ldots, l_{6} \leq m_{6} \leq u_{6}$ & $u_{5}$ & 0.2333901 \\
\hline$\left|u_{2-} 3.5 * l_{6}\right| \leq k * l_{6}$ & $l_{2}>0, \ldots, l_{6}>0$ & $l_{6}$ & 0.1168633 \\
\hline & & $m_{6}$ & 0.1168633 \\
\hline & & $u_{6}$ & 0.1451313 \\
\hline
\end{tabular}

Table 10

Deffuzified weights

\begin{tabular}{lcc}
\hline$C R$ & 0.0839391 & for all experts \\
\hline$W_{C 2}$ & 0.2947036 & 0.2732036 \\
$W_{C 3}$ & 0.1606736 & 0.1756736 \\
$W_{C 4}$ & 0.1896582 & 0.1916582 \\
$W_{C 5}$ & 0.2333901 & 0.2248901 \\
$W_{C 6}$ & 0.1215746 & 0.1345746 \\
$C R$ & 0.0839391 & for all experts \\
\hline
\end{tabular}


Table 11

Results of calculating the matrix W22

\begin{tabular}{cccccc}
\hline & $\mathrm{C} 1$ & $\mathrm{C} 2$ & $\mathrm{C} 3$ & $\mathrm{C} 4$ & $\mathrm{C} 5$ \\
\hline $\mathrm{C} 1$ & 0 & 0 & 0 & 0 & 0 \\
$\mathrm{C} 2$ & 0.2732036 & 0 & 0.4216322 & 0.5125032 & 0.432556 \\
$\mathrm{C} 3$ & 0.1756736 & 0.3713472 & 0 & 0.281425 & 0.1807155 \\
$\mathrm{C} 4$ & 0.1916582 & 0.40550633 & 0.3165542 & 0 & 0.223558 \\
$\mathrm{C} 5$ & 0.2248901 & 0 & 0 & 0 & 0 \\
C6 & 0.1345746 & 0.22314927 & 0.2618136 & 0.2060718 & 0.1631705 \\
\hline
\end{tabular}

As a sample, the procedures performed for W21 and W22 are mentioned. The same calculations were applied for W23 and W32. Finally, the weights were obtained and the super-matrix was completed. The placement of the four obtained matrices into the initial super-matrix is presented in Table 12. The limiting super-matrix can be seen in Table 13.

Table 12

Unweighted Super-matrix

\begin{tabular}{cccccccccccc}
\hline & $G$ & $C 1$ & $C 2$ & $C 3$ & $C 4$ & $C 5$ & $C 6$ & $A 1$ & $A 2$ & $A 3$ & $A 4$ \\
\hline$G$ & - & - & - & - & - & - & - & - & - & - & - \\
$C 1$ & 0.1058 & 0.0000 & 0.0000 & 0.0000 & 0.0000 & 0.0000 & 0.0000 & 0.1182 & 0.1080 & 0.1284 & 0.0981 \\
$C 2$ & 0.2878 & 0.2732 & 0.0000 & 0.4216 & 0.5125 & 0.4326 & 0.0000 & 0.3013 & 0.3096 & 0.2931 & 0.3176 \\
$C 3$ & 0.1038 & 0.1757 & 0.3713 & 0.0000 & 0.2814 & 0.1807 & 0.0000 & 0.1174 & 0.1071 & 0.1277 & 0.0971 \\
$C 4$ & 0.1603 & 0.1917 & 0.4055 & 0.3166 & 0.0000 & 0.2236 & 0.0000 & 0.1547 & 0.1530 & 0.1564 & 0.1514 \\
$C 5$ & 0.2610 & 0.2249 & 0.0000 & 0.0000 & 0.0000 & 0.0000 & 0.0000 & 0.2249 & 0.2410 & 0.2088 & 0.2566 \\
$C 6$ & 0.0813 & 0.1346 & 0.2231 & 0.2618 & 0.2061 & 0.1632 & 0.0000 & 0.0835 & 0.0814 & 0.0856 & 0.0793 \\
$A 1$ & - & 0.1565 & 0.1423 & 0.1797 & 0.1610 & 0.1945 & 0.1840 & - & - & - & - \\
$A 2$ & - & 0.1768 & 0.1655 & 0.1246 & 0.1450 & 0.0935 & 0.1079 & - & - & - & - \\
$A 3$ & - & 0.4602 & 0.4710 & 0.4154 & 0.4432 & 0.5134 & 0.5049 & - & - & - & - \\
$A 4$ & - & 0.2065 & 0.2213 & 0.2803 & 0.2508 & 0.1987 & 0.2032 & - & - & - & - \\
\hline
\end{tabular}

Table 13

Limiting Super-matrix

\begin{tabular}{|c|c|c|c|c|c|c|c|c|c|c|c|}
\hline & G & $\mathrm{C} 1$ & $\mathrm{C} 2$ & C3 & C4 & $\mathrm{C} 5$ & C6 & A1 & A2 & A3 & A4 \\
\hline G & 0.0000 & 0.0000 & 0.0000 & 0.0000 & 0.0000 & 0.0000 & 0.0000 & 0.0000 & 0.0000 & 0.0000 & 0.0000 \\
\hline $\mathrm{C} 1$ & 0.0425 & 0.0425 & 0.0425 & 0.0425 & 0.0425 & 0.0425 & 0.0425 & 0.0425 & 0.0425 & 0.0425 & 0.0425 \\
\hline $\mathrm{C} 2$ & 0.1887 & 0.1887 & 0.1887 & 0.1887 & 0.1887 & 0.1887 & 0.1887 & 0.1887 & 0.1887 & 0.1887 & 0.1887 \\
\hline $\mathrm{C} 3$ & 0.1064 & 0.1064 & 0.1064 & 0.1064 & 0.1064 & 0.1064 & 0.1064 & 0.1064 & 0.1064 & 0.1064 & 0.1064 \\
\hline $\mathrm{C} 4$ & 0.1250 & 0.1250 & 0.1250 & 0.1250 & 0.1250 & 0.1250 & 0.1250 & 0.1250 & 0.1250 & 0.1250 & 0.1250 \\
\hline $\mathrm{C} 5$ & 0.0870 & 0.0870 & 0.0870 & 0.0870 & 0.0870 & 0.0870 & 0.0870 & 0.0870 & 0.0870 & 0.0870 & 0.0870 \\
\hline C6 & 0.0880 & 0.0880 & 0.0880 & 0.0880 & 0.0880 & 0.0880 & 0.0880 & 0.0880 & 0.0880 & 0.0880 & 0.0880 \\
\hline A1 & 0.0610 & 0.0610 & 0.0610 & 0.0610 & 0.0610 & 0.0610 & 0.0610 & 0.0610 & 0.0610 & 0.0610 & 0.0610 \\
\hline A 2 & 0.0486 & 0.0486 & 0.0486 & 0.0486 & 0.0486 & 0.0486 & 0.0486 & 0.0486 & 0.0486 & 0.0486 & 0.0486 \\
\hline A 3 & 0.1708 & 0.1708 & 0.1708 & 0.1708 & 0.1708 & 0.1708 & 0.1708 & 0.1708 & 0.1708 & 0.1708 & 0.1708 \\
\hline A4 & 0.0824 & 0.0824 & 0.0824 & 0.0824 & 0.0824 & 0.0824 & 0.0824 & 0.0824 & 0.0824 & 0.0824 & 0.0824 \\
\hline
\end{tabular}

As it can be seen, ranking of criteria and alternatives are shown in Tables 14 .

Table 14

Ranking of criteria and alternatives

\begin{tabular}{ccc}
\hline Criteria & F-BWANP Weights & Ranking \\
\hline C2 & 0.1887 & 1 \\
C4 & 0.1250 & 2 \\
C3 & 0.1064 & 3 \\
C6 & 0.0880 & 4 \\
C5 & 0.0870 & 5 \\
C1 & 0.0425 & 6 \\
\hline
\end{tabular}




\begin{tabular}{ccc}
\hline Alternatives & F-BWANP Weights & Ranking \\
\hline A3 & 0.1708 & 1 \\
A4 & 0.0824 & 2 \\
A1 & 0.0610 & 3 \\
A2 & 0.0486 & 4 \\
\hline
\end{tabular}

\section{Discussion and conclusions}

In this paper, some problems of F-ANP method were described and then, F-BWANP method was proposed as the alternative. The proposed method, requires less comparison data and leads to more consistent comparisons, which means that more reliable results can be obtained. F-BWANP is a vectorbased method that requires fewer comparisons compared to the F-ANP matrix-based method. For FBWANP, we only need to have 2n-3 comparisons while for F-ANP, n(n-1)/2 comparisons are needed. In this paper, it has been shown that the proposed method is preferred to F-ANP due to the significant decrease in pair-wise comparisons and calculations and also calculating more reliable final weights.

\section{References}

Agarwal, A., Shankar, R., \& Tiwari, M. (2006). Modeling the metrics of lean, agile and leagile supply chain: An ANP-based approach. European Journal of Operational Research, 173(1), 211-225.

Aznar, J., Ferrís-Oñate, J., \& Guijarro, F. (2010). An ANP framework for property pricing combining quantitative and qualitative attributes. Journal of the Operational Research Society, 61(5), 740-755.

Blair, A. R., Nachtmann, R., Saaty, T. L., \& Whitaker, R. (2002). Forecasting the resurgence of the US economy in 2001: an expert judgment approach. Socio-Economic Planning Sciences, 36(2), 77-91.

Büyüközkan, G., Ertay, T., Kahraman, C., \& Ruan, D. (2004). Determining the importance weights for the design requirements in the house of quality using the fuzzy analytic network approach. International Journal of Intelligent Systems, 19(5), 443-461.

Chang, A.-Y., Hu, K.-J., \& Hong, Y.-L. (2013). An ISM-ANP approach to identifying key agile factors in launching a new product into mass production. International Journal of Production Research, 51(2), 582-597.

Chang, C.-W., Wu, C.-R., \& Chen, H.-C. (2009a). Analytic network process decision-making to assess slicing machine in terms of precision and control wafer quality. Robotics and Computer-Integrated Manufacturing, 25(3), 641-650.

Chang, Y.-H., Wey, W.-M., \& Tseng, H.-Y. (2009b). Using ANP priorities with goal programming for revitalization strategies in historic transport: A case study of the Alishan Forest Railway. Expert Systems with Applications, 36(4), 8682-8690.

Chen, H. H., Kang, H.-Y., Xing, X., Lee, A. H., \& Tong, Y. (2008). Developing new products with knowledge management methods and process development management in a network. Computers in Industry, 59(2), 242-253.

Chen, J.-K., \& Chen, I. S. (2009). Performance Evaluation for the Banking Industry in Taiwan Based on Total Quality Management.

Chen, R. S., Shyu, J. Z., \& Tzeng, G. H. (2006). The Policy of High-Tech Industry Development: The Case of Location Assessment for Biotech Industry Parks in Taiwan. Review of Policy Research, 23(2), 589-606.

Chen, Z., Li, H., Ross, A., Khalfan, M. M., \& Kong, S. C. (2008). Knowledge-driven ANP approach to vendors evaluation for sustainable construction. Journal of construction Engineering and Management, 134(12), 928-941. 
Cheng, E. W., \& Li, H. (2005). Analytic network process applied to project selection. Journal of construction Engineering and Management, 131(4), 459-466.

Cheng, E. W., Li, H., \& Yu, L. (2005). The analytic network process (ANP) approach to location selection: a shopping mall illustration. Construction Innovation, 5(2), 83-97.

Crowe, S., \& Lucas-Vergona, J. (2007). What should be done about the illegal immigration from Mexico to the United States? Mathematical and Computer Modelling, 46(7), 1115-1129.

Guo, S., \& Zhao, H. (2017). Fuzzy best-worst multi-criteria decision-making method and its applications. Knowledge-Based Systems, 121, 23-31.

Hämäläinen, R. P., \& Seppäläinen, T. O. (1986). The analytic network process in energy policy planning. Socio-Economic Planning Sciences, 20(6), 399-405.

Hülle, J., Kaspar, R., \& Möller, K. (2013). Analytic network process-an overview of applications in research and practice. International Journal of Operational Research, 16(2), 172-213.

Lee, A. H., Chen, H. H., \& Tong, Y. (2008). Developing new products in a network with efficiency and innovation. International Journal of Production Research, 46(17), 4687-4707.

Lee, H., Lee, C., Seol, H., \& Park, Y. (2008). On the R\&D priority setting in technology foresight: a DEA and ANP approach. International Journal of Innovation and Technology Management, 5(02), 201-219.

Pal, D., Ravi, B., \& Bhargava, L. (2007). Rapid tooling route selection for metal casting using QFDANP methodology. International Journal of Computer Integrated Manufacturing, 20(4), 338-354.

Saaty, T. L. (1996). Decision making with dependence and feedback: The analytic network process (Vol. 4922): RWS publications Pittsburgh.

Saaty, T. L. (2001). Analytic network process Encyclopedia of Operations Research and Management Science (pp. 28-35): Springer.

Saaty, T. L. (2005). Theory and applications of the analytic network process: decision making with benefits, opportunities, costs, and risks: RWS publications.

Saaty, T. L., \& Brandy, C. (2009). The encyclicon, volume 2: a dictionary of complex decisions using the analytic network process. Pittsburgh, Pennsylvania: RWS Publications.

Sadjadi, S., \& Karimi, M. (2018). Best-worst multi-criteria decision-making method: A robust approach. Decision Science Letters, 7(4), 323-340.

Sipahi, S., \& Timor, M. (2010). The analytic hierarchy process and analytic network process: an overview of applications. Management Decision, 48(5), 775-808.

Vargas, L. G. (2006). Decision Making with the Analytic Networt Process: Economic, Political, Social and Technological Applications with Benefits, Opportunities, Costs and Risks. International Series in Operations Research and Management Science: Springer.

Wadhwa, S., Mishra, M., \& Chan, F. T. (2009). Organizing a virtual manufacturing enterprise: an analytic network process based approach for enterprise flexibility. International Journal of Production Research, 47(1), 163-186.

Wu, C.-R., Lin, C.-T., \& Tsai, P.-H. (2009). Analysing alternatives in financial services for wealth management banks: the analytic network process and the balanced scorecard approach. IMA Journal of Management Mathematics, 20(3), 303-321.

Yu, R., \& Tzeng, G.-H. (2006). A soft computing method for multi-criteria decision making with dependence and feedback. Applied mathematics and computation, 180(1), 63-75.

Zoffer, J., Bahurmoz, A., Hamid, M. K., Minutolo, M., \& Saaty, T. (2008). Synthesis of complex criteria decision making: a case towards a consensus agreement for a Middle East conflict resolution. Group Decision and Negotiation, 17(5), 363-385.

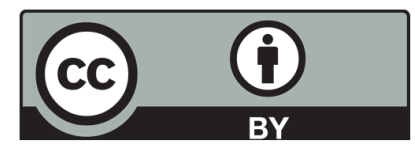

(C) 2019 by the authors; licensee Growing Science, Canada. This is an open access article distributed under the terms and conditions of the Creative Commons Attribution (CC-BY) license (http://creativecommons.org/licenses/by/4.0/). 